\title{
VIOLÊNCIA E INDISCIPLINA NA ESCOLA: UM COTEJO NECESSÁRIO
}

Natália Branco Lopes KRAWCZUN ${ }^{1}$

Adreana Dulcina PLATT ${ }^{2}$

RESUMO: Esse estudo tem a intenção de cotejar os principais aspectos dos fenômenos da violência e da indisciplina no espaço escolar. Entendemos a relevância do tema uma vez que a atual realidade apresenta aspectos que ultrapassam questões antes enfrentadas nas escolas como indisciplina para serem retratadas como atos de extrema violência. Para caracterizar os fenômenos realizamos uma pesquisa bibliográfica, documental e investigativa junto aos atores diretamente envolvidos, apoiados na instrumentalidade técnica de entrevistas e questionários. Num segundo momento, fazemos um levantamento doutrinário da "fala" do Pode Público Estatal para coibir tais fenômenos junto às escolas. No último capítulo, destacamos uma das ações propostas como atuação efetiva junto às unidades de ensino. Nesse sentido, destacamos o programa da patrulha escolar do Estado do Paraná, em particular, na cidade de Londrina.

PALAVRAS-CHAVE: Violência. Indisciplina. Escola.

\section{Introdução}

A violência que abala a sociedade em todos os seus setores repercute nas escolas das mais variadas formas. Demarcar essas variáveis é imprescindível para delimitar este fenômeno que possui características a ele inerentes e distintas das manifestações de atitudes problemáticas relacionadas à indisciplina.

Diante do quadro, é temerário que a insuficiência de compreensão da própria realidade ocasione um afastamento da análise cuidadosa de fenômenos isolados e, na conjuntura, de forma ampliada, resultando em generalizações indevidas.

Assim, com o objetivo de verificar a clara compreensão da escola, em relação à indisciplina e violência, esse estudo pretende bordar os elementos acima identificados para que, além de colher informações existentes na literatura, venha a apresentar uma pesquisa qualitativa, baseada em depoimentos de policiais militares que atuam na Patrulha Escolar Comunitária na cidade de Londrina (PR) e região, bem como de professores vinculados à rede estadual de ensino do município de Londrina (PR).

\footnotetext{
${ }^{1}$ Mestre em Educação. Docente. FAAT - Faculdade Arthur Thomas. Londrina - PR - Brasil. 86061-450 nataliabrancoprof@hotmail.com.

${ }^{2}$ Doutora em Educação. UNICAMP - Universidade Estadual de Campinas. Professora Adjunta. UEL Universidade Estadual de Londrina. Londrina - PR - Brasil. 86057-970 - adplatt@uel.br.
} 
Os depoimentos de policiais da Patrulha Escolar foram colhidos no dia 19 de agosto de 2009 na sede da $4^{\text {a }}$ companhia do batalhão da Patrulha Escolar Comunitária de Londrina, Paraná, com o interesse de verificar, na concepção da polícia, se a escola possui claro entendimento sobre o conceito de indisciplina e de violência.

As entrevistas dirigidas aos professores foram realizadas com o intuito de fazer um cotejo com o material previamente colhido. Para isso, trinta questionários foram enviados a professores da rede estadual e municipal de Londrina, sendo que apenas três responderam à pesquisa, totalizando assim, o material coletado para a apresentação de dados e realização da análise aqui proposta.

\section{O "mal estar" da humanidade}

Bauman (2001, p.10) metaforicamente aponta a "liquidez" ou "fluidez" como a "consistência da sociedade moderna", em que ao "derreter os sólidos" desintegrou as "lealdades tradicionais, direito costumeiro e das obrigações que atavam os pés e mãos, impediam os movimentos e restringiam as iniciativas", ou como dizia Weber apud Baumann, (2001, p.10) “[...] liberou-se a empresa de negócios dos grilhões, dos deveres com a família e o lar e da densa trama das obrigações éticas", desembocando no surgimento de uma nova ordem altamente flexível ou "fluida".

Cortella e La Taille (2009) ao realizar uma simples distinção entre "comunidade" e "agrupamento", demonstra de forma esclarecedora como as relações sociais têm se desenvolvido numa nova ordem de "fluidez" em que as constantes quebras de valores morais como a honra e o respeito têm abalado as relações intersubjetivas em todas as instâncias, inclusive nas escolas.

Conforme salienta Cortella e La Taille (2009), os agrupamentos têm subsistido em detrimento das comunidades. Para se ter uma comunidade, um grupo de pessoas compartilha dos mesmos objetivos e, unidas, desenvolvem um mecanismo de “[...] autopreservação e estruturas de proteção recíproca." (CORTELLA; LA TAILLE, 2009, p.32). Enquanto que em agrupamentos, as relações consistem numa junção de pessoas cujos objetivos coincidem, porém sem os “[...] mecanismos de proteção recíproca nem estruturas de preservação".

De acordo com Cortella e La Taille (2009), ressalta-se o individualismo como uma das características da sociedade contemporânea, cujas consequências têm sido no mínimo questionáveis. Para o autor, o entendimento de alteridade tem sido 
constantemente deturpado, pois o respeito ao outro, como um indivíduo diferente passa a não possuir mais o valor moral que lhe é devido.

O que parece estar ocorrendo na sociedade moderna, é que “[...] estamos vivendo uma certa volta à intolerância de outras épocas". (CORTELLA; LA TAILLE, 2009, p.28).

Assim, Cortella e La Taille (2009) acrescentam que "tolerância" é um sentimento que tem ocupado o lugar de acolhimento. Não há mais "acolhimento" ao sujeito que difere de um determinado grupo; o que tem ocorrido é que, baseado na indiferença, um suporta, aguenta o outro, relacionando-se superficialmente. Nesse sentido, ponderam que “[...] o individualismo prevalece: as pessoas se retraem nas tribos, nos grupos. E aí reside um perigo: isso cria muito mais, digamos, "raiva" do outro, do que realmente apego à própria tribo" (CORTELLA; LA TAILLE, 2009, p.27), sendo este um entre muitos motivos que impulsionam os campos de tensões da sociedade contemporânea.

\section{A indisciplina: um bem necessário, um mal desnecessário}

De acordo com o dicionário de língua portuguesa de Bueno (2007, p.432), por "indisciplina" significamos situações de "desobediência, rebelião e insubordinação". Apesar de a análise superficial do significado da palavra gerar uma impressão negativa quanto ao ato de indisciplina, importante se faz tecer algumas considerações quanto ao assunto, vez que a indisciplina, assim como a violência, também é parte constituinte da natureza humana, podendo ela inclusive ser considerada como ingrediente essencial para viabilizar os movimentos sociais.

Nesse sentido, Thompson (1987) ao analisar os motins de operários frente às imposições do empresariado - donos de grandes capitais -, e uma vez considerando como inaceitável qualquer manobra econômica voltada ao aumento do preço dos alimentos, entendeu essa reação como “[...] uma consciência de consumidor que retrata um esforço desesperado do povo para reimpor a economia moral mais antiga, em detrimento da economia de livre mercado".

Moore Jr. (1987, p.123) assinala a mudança do contrato social como uma "[...] superação da autoridade moral do sofrimento e da opressão". Assim, para que haja a quebra de um sistema social opressivo, muitas vezes um grupo tem que se unir para 
protestar em busca da justiça, ou seja, um grupo de pessoas passa a rejeitar e opor-se à ordem social vigente. Assim, de acordo com Moore Jr. (1987, p.124):

O processo fundamental de transformação cultural consiste num solapamento do sistema de crenças vigente, que confere legitimidade, ou pelo menos naturalidade a algum grau de correspondência com as expectativas comuns, à ordem social existente. $\mathrm{Na}$ área da estrutura social, corresponde à criação de uma presença política efetiva, alguma forma de organização para se contrapor à autoridade organizada [...].

Remetendo-se às manifestações no Brasil, o processo de redemocratização foi marcado pela resistência e luta política social.

Outro exemplo cronologicamente mais próximo ocorreu em 1992, na ocasião em que os estudantes em manifestação pelo impeachment ao presidente Fernando Collor de Mello demonstram uma reação popular, podendo ser considerada como um ato de indisciplina contra a mais alta instância do Poder Executivo (MEMÓRIA E MOVIMENTO SOCIAIS, s.d.).

A perspectiva salutar da indisciplina possui, de certa forma, conexão com as palavras de Freire (apud LUCKESI, 1994, p.86) ao propor uma educação capaz de libertar o indivíduo, ressaltando que a finalidade da escola não deveria ser a da manutenção do status quo do sujeito, mas a de proporcionar a ele as condições necessárias para o seu ingresso num processo de tomada crítica, para que ele seja um "sujeito de sua própria educação" e "instrumento de ajuste na sociedade".

Não obstante a indisciplina possa ser vista por um enfoque salutar, é importante salientar seus efeitos, também existentes, sob uma ótica destrutiva.

Nesse sentido, Cortella e La Taille (2009) salientam a ausência de autocontrole como um dos fatores mais significativos da indisciplina. Assim, à medida que o indivíduo sabe que determinada atitude, embora desejada, não seja correta, ele não consegue, ou nem ao menos faz questão de conter os seus impulsos. De acordo com o autor, a falta de respeito pelo outro passa a ser inclusive uma questão que pertence ao campo da moral, da necessidade de pensar no bem da coletividade, assim como seria, por exemplo, silenciar-se no momento em que o professor explica o conteúdo.

Nota-se que comparando o segundo enfoque de indisciplina com o primeiro, silenciar-se para ouvir uma explicação que é importante para a compreensão de todos os colegas não significa estar alienado a uma ordem opressora imposta, mas sim uma atitude de respeito para com o outro e até mesmo para consigo mesmo. 
Assim, de acordo com a consideração exposta acima, é essencial a realização de uma análise consistente quanto às motivações do ato de indisciplina, pois em alguns momentos, diferentemente do reprovável, a indisciplina pode ser vista como necessária para o bem comum.

\section{A instituição escolar como um espaço de conflitos}

De acordo com Debarbieux (apud ABRAMOVAY, 2002), a escola, por ser um espaço extremamente heterogêneo e, portanto, desigual, é um campo fértil de constantes tensões. Chrispino (2008) assinala que a massificação da escola é um fenômeno com o qual a instituição não está historicamente preparada para lidar. Habituada a lidar com iguais, a escola abriga uma diversidade discrepante em que os "[...] antagonicismos que se transformam em conflitos e que podem chegar ao extremo da violência" (CHRISPINO, 2008, p.23), assolam o convívio escolar.

E nesse caldeirão, conforme salienta Debarbieux (apud ABRAMOVAY, 2002), os direitos atribuídos aos desiguais são os mesmos, porém, os deveres impostos são desiguais, fazendo com que a situação fique ainda mais delicada.

É bem verdade que a escola tem sido considerada como um campo minado cujas relações entre alunos e alunos e professores tem sido cada vez mais tensas. Nesse sentido, Aquino $(1998$, p.8) pondera que:

A imagem entre nós já quase idílica, da escola como lócus de fomentação do pensamento humano - por meio da recriação do legado cultural - parece ter sido substituída, grande parte das vezes, pela visão difusa de um campo de pequenas batalhas civis; pequenas, mas visíveis o suficiente para causar uma espécie de mal-estar coletivo [...].

Conforme já foi abordado anteriormente, as relações sociais são extremamente complicadas e constantemente traçadas por atritos de diversas naturezas. Em meio a esses obstáculos ainda há de se considerar as questões de ordem macro-estruturais que influenciam o âmbito escolar e, sob esse enfoque a escola seria marcada por uma espécie de "reprodução difusa" dos contextos provenientes, por exemplo, da economia, política, da mídia, das relações familiares que estão fora dos muros da instituição (AQUINO, 1998).

É bem certo que equivocada seria a desconsideração dos efeitos das relações que ocorrem dentro do espaço escolar. O que parece ocorrer de fato é que os reflexos de fatores externos à escola, somados aos de natureza interna, constituem uma mistura bombástica na díade indisciplina/violência.

\section{A violência nas escolas}


O restrito entendimento de que a violência na escola é causada pelos mais variados processos sociais atingem diretamente a escola devido à vulnerabilidade da instituição a todas as espécies de processos. Segundo Abramovay et al. (2005), para a realização de uma análise satisfatória sobre o tema, é necessário relativizar a visão de que a violência na escola é apenas um reflexo de processos sociais mais amplos, abrindo-se a possibilidade para abordar, também, a violência como um fenômeno produzido "na e pela escola".

Nesse sentido Debarbieux (apud ABRAMOVAY; RUA, 2003) afirma que a violência nas escolas pode ocorrer em três dimensões: A primeira relaciona-se com as estruturas deficientes que decorrem da dificuldade de gestão nas escolas; a segunda relaciona-se ao contexto social, em que a escola é invadida por gangues, pelo tráfico de drogas, bem como pela exclusão social; por último, o autor menciona componentes internos, específicos de cada instituição.

A escola tem convivido com situações em que as transgressões que se apresentam com os mais variados níveis de gravidade têm-se tornado cada vez mais presentes, dirigindo-se contra a pessoa, à propriedade e contra o patrimônio (ABRAMOVAY; RUA, 2003).

A violência contra a pessoa pode ser realizada de forma verbal ou física, por meio de, por exemplo, ameaças, socos, chutes, violência sexual e emprego de armas de fogo (ABRAMOVAY; RUA, 2003).

A violência contra o patrimônio, de acordo com Abramovay e Rua (2003), consiste na depredação do espaço escolar. Pichações nas paredes, portas de banheiros, depredações de muros, paredes, explosões de bombas no recinto escolar são exemplos comuns que demonstram a falta de cuidado com o bem comum.

Nos casos em que há violência contra a propriedade, as autoras salientam os roubos e furtos como as práticas mais corriqueiras nas escolas. A prática parece ter se tornado tão comum que os alunos diretores e coordenadores, de modo geral, já não dão mais ao fato sua devida importância (ABRAMOVAY; RUA, 2003).

Quanto à banalização da violência, Candau (2000, p.151) realiza a seguinte análise:

A violência está se tornando tão constante e cada vez mais frequente no dia-a-dia, que nem se reconhece pequenos atos como violentos, o que agrava a situação. Na medida em que esses pequenos atos passam a ser considerados normais devido à sua frequência, acaba-se 
banalizando a violência, o que contribui para formar hábitos e atitudes que cada vez mais são influenciados pela agressão e pelo desrespeito o outro.

De acordo com Charlot (apud ABRAMOVAY; RUA, 2003, p.22) a violência escolar pode ser classificada em três níveis. O primeiro é o que o autor denomina por "violência", que implica em "[...] atos como golpes, ferimentos, roubos, crimes, vandalismo e violência sexual". A segunda classificação pontuada pelo autor é a da "incivilidade", que pressupõe a humilhação e a falta de respeito. A terceira categoria elencada é denominada como "violência simbólica ou institucional" que é compreendida como a "falta de sentido de permanecer na escola por tantos anos", o ensino passa a ser um constante desprazer aos alunos que, se obrigam a estudar conteúdos que não condizem com seus interesses, além de enfrentar uma sociedade que não os acolhe no mercado de trabalho e professores insatisfeitos que enfrentam o serviço como uma obrigação frente aos desinteresses dos alunos. A violência simbólica é a mais difícil de ser percebida, muitas vezes não percebida pela própria vítima.

A escola impõe padrões, ritmos, normas e regras, muitas vezes, desconsiderando a multiplicidade de referências culturais e identidades provenientes da juventude, enxergando-os somente como alunos. Esse descompasso entre a cultura da escola e a do jovem é percebido claramente no plano da violência de cunho institucional, pautando o seu sistema de convivência em normas inflexíveis e regras autoritárias e, nessa perspectiva, a violência na escola pode ser compreendida como resultante da inadequação das relações entre os membros compositores da comunidade escolar (ABRAMOVAY et al., 2005).

Para Bourdieu, a violência simbólica baseia-se nas trocas desiguais praticamente imperceptíveis uma vez que “[...] se exerce com a cumplicidade tácita dos que a sofrem e também com a frequência dos que a exercem, na medida em que uns e outros são inconscientes de exercê-la e de sofrê-la." (apud GOMES; FONSECA, 2005). A submissão discreta e silenciosa escondida entre os limites impostos possui o potencial de gerar na vítima sentimentos que variam da ansiedade, vergonha e humilhação a respeito, amor e admiração (GOMES; FONSECA, 2005).

Estudiosos da violência classificaram diversas formas de apresentação e ocorrência nas escolas públicas e privadas ressaltando a presença de gangues, de armas 
e do tráfico de drogas nas instituições escolares, agressões contra professores e o bullying $^{3}$, que pode ocorrer de forma direta e indireta (ANTUNES; ZUIM, 2008).

O bullying é uma espécie de violência que possui características muito peculiares, cuja pontualidade pode ser definida da seguinte forma:

No caso do bullying há uma forte intenção de ofensa ao outro e isso
parte do pressuposto de que o agressor tem alguma prioridade em
relação à vítima como, por exemplo, alunos mais velhos e/ou
fisicamente mais fortes que agridem alunos mais novos e/ou mais
fracos, reduzindo as chances de defesa da vítima. Resumindo, um
aluno é vítima de bullying quando está exposto constantemente e
durante boa parte do tempo a ações negativas por parte de um aluno
ou por um grupo de alunos. (RUOTTI; ALVES; CUBAS, 2006, p.35).

Este comportamento normalmente volta-se a grupos com alguma característica física diferenciada: socio-econômica, etnia, homossexuais ou filhos de homossexuais, alunos obesos, de baixa estatura ou com qualquer outro aspecto que diferencie da maioria dos colegas (ANTUNES; ZUIM, 2008).

$\mathrm{O}$ ato violento, em especial, tem sido objeto de estudos específicos e divulgados frequentemente pela mídia. Interessante mencionar que esses rompantes de agressividade, sem possuírem qualquer motivo aparente, costumam ocorrer por repetidas vezes por uma pessoa ou grupo mais forte que vitimiza o outro indefeso (ANTUNES; ZUIM, 2008).

Pontuando de forma mais precisa a violência nas escolas, Abramovay e Rua (2003) esclarecem que mesmo na escola ocorrem os mais variados tipos de violência. Devido ao clima de intimidação, a ameaça ocorre com frequência, causando sentimento de insegurança entre alunos e funcionários da instituição. As brigas, de acordo com as autoras, representam uma das modalidades mais corriqueiras de violência nas escolas. "Briga-se por futebol, lanche, notas, por causa de apelidos e tomada de objetos um dos outros”. (ABRAMOVAY; RUA, 2003, p.51). O uso de armas, a agressão dirigida aos professores a violência sexual, a violência contra a propriedade, contra o patrimônio são espécies de violência que têm feito parte do cotidiano escolar.

Em relação à temática, Candau (2000) aponta que os professores têm sido tomados pelo sentimento de insegurança, pois para eles a violência tem aumentado nas escolas não apenas sob uma perspectiva quantitativa, mas também qualitativa, ao passo

\footnotetext{
${ }^{3}$ Denominação inglesa surgida na década de 1970 na Noruega (ANTUNES; ZUIM, 2008).
} 
que a diversificação e a intensidade com que a violência tem crescido nas escolas são perceptíveis a todos os atores que a compõem.

Embora os noticiários e as pesquisas demonstrem um elevado índice de criminalidade nas escolas, Debarbieux et al. (2003) salienta que as estatísticas que são consideradas alarmantes não revelam este índice em sua totalidade, vez que o diretor, no anseio de proteger a reputação da escola, nem sempre revela as infrações às instâncias hierarquicamente superiores, assim como as vítimas, que, muitas vezes, por medo ou vergonha, não registram o fato ocorrido. Assim, as estatísticas oficiais não correspondem aos dados reais: “[...] elas deixam uma cifra negra, que corresponde à indiferença entre a delinquência total e a delinquência registrada" (DEBARBIEUX et al., 2003, p.13).

\section{A indisciplina nas escolas}

Segundo Dayan (2008), durante os séculos XIX e XX, o autoritarismo era inerente à figura do professor. As regras eram simplesmente impostas, não havia espaço para discussão ou qualquer outra forma de manifestação democrática na sala de aula. Aos alunos cabia a tarefa de submeter-se às normas, sem questioná-las. Ainda que timidamente, já havia indisciplina nas escolas, mas não como mas não como um dos problemas mais significativos da educação. O conceito de indisciplina não é unívoco, podendo variar nas diferentes classes sociais, regiões e diferentes culturas, justamente pelo fato de constituir uma criação cultural. Assim, para um professor mais tolerante, um ato de indisciplina pode ser considerado irrelevante, enquanto que para um professor mais rigoroso, um ato comum pode ser por ele interpretado como um ato de indisciplina (DAYAN 2008).

Embora a indisciplina sempre tenha existido, ela nunca foi considerada como um entrave tão significativo para a educação como nos dias atuais. As condutas indisciplinadas alastraram-se em proporções jamais vistas, cujas causas advêm de uma multiplicidade de fatores que se interligam; “[...] as crianças já não obedecem mais, a ideia de limites desapareceu, a sociedade se transformou, as crianças também mudaram.” (DAYAN, 2008, p.19).

Libâneo (1994, p.251) considera a necessidade de o docente estar atento a dois aspectos fundamentais para a sua interação com seus alunos: "o aspecto cognoscitivo (que diz respeito à forma de comunicação dos conteúdos escolares e às tarefas escolares 
indicadas aos alunos)" e o "aspecto sócio-emocional (que diz respeito às relações pessoais entre o professor e aluno e às normas disciplinares indispensáveis ao trabalho docente)". Assim, na relação entre o professor e seus alunos é importante que na busca pela ordem necessária para que as atividades sejam desenvolvidas de forma satisfatória, o professor tenha consciência da necessidade de "combinar severidade com respeito" (LIBÂNEO, 1994, p.251). A autoridade que o professor exerce, além de constituir um atributo inerente às suas qualidades, é também, segundo o autor, um instrumento valioso para estimular a ação educativa.

O psicólogo docente da Universidade de São Paulo, Lino de Macedo, acrescenta

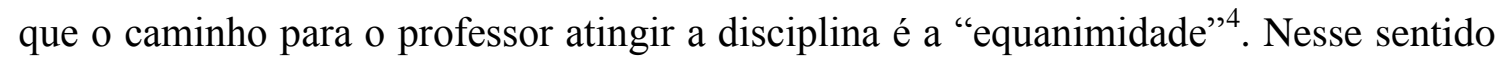
Rios (2008), além de afirmar que o autoritarismo constitui o grande entrave para que a disciplina flua em uma sala, aponta a necessidade de o professor estabelecer entre seus alunos uma relação amistosa.

\section{O Cotejo entre indisciplina e violência}

A abordagem da temática "violência" requer uma análise muito cuidadosa. A definição do que é a violência escolar está em construção, suscitando uma série de discussões entre os pesquisadores do assunto. Nesse sentido Debarbieux (2001 apud RUOTTI; ALVES; CUBAS, 2006), pondera a necessidade de delimitar cientificamente o real significado de violência nas escolas, devido à amplitude do termo. Não é rara a confusão entre os termos violência e indisciplina até mesmo dentro do ambiente escolar, pois:

Quando se faz uso de um termo tão amplo como "violência" que
abrange desde agressões graves até pequenas incivilidades que
acontecem na escola, o problema pode tornar-se impensável devido
aos inúmeros tipos de situações envolvidas ou pode, simplesmente,
passar a criminalizar, estigmatizar padrões de comportamentos
comuns ao ambiente escolar (RUOTTI; ALVES; CUBAS, 2006,
p.24). De acordo com Ballion (apud DAYAN, 2008), a violência é um problema da polícia e do Poder Judiciário, enquanto que a indisciplina é problema para ser resolvido no âmbito escolar. A violência que ocorre nas escolas, assim como a que ocorre fora das escolas, são crimes e delitos cujas sanções estão prescritas no Código Penal, não podendo ser comparadas com as conversas de alunos em momentos inadequados,

\footnotetext{
${ }^{4}$ Equanimidade: Serenidade de espírito; justiça; ponderação; prudência (BUENO, 2007, p.304).
} 
atrasos de alunos, pois a indisciplina trata-se da não observância de regras estabelecidas para garantir o bom andamento das atividades na sala de aula (DAYAN, 2008).

Ruotti, Alves e Cubas (2006, p.67), expõem em seu livro uma pesquisa realizada com base na leitura de livros ou cadernos de registros de atos indisciplinares e concluem a análise da seguinte forma:

\begin{abstract}
A leitura desses livros e cadernos indicou quanto o cotidiano escolar é permeado por agressões verbais, agressões físicas leves (chutes, tapas, empurrões), desrespeito às regras escolares, destruição do patrimônio escolar, não realização de atividades escolares, alunos que cabulam aulas (grifo nosso).
\end{abstract}

Nesse momento, importante se faz salientar a existência da confusão por parte dos profissionais que atuam nas escolas quanto ao conceito de violência com o de um ato de indisciplina. As palavras grifadas na citação exposta é a comprovação dessa afirmação, que demonstra que a associação de indisciplina com agressividade e violência faz com que o problema fique fora do alcance do conhecimento pedagógico.

O conceito de disciplina implica a flexibilidade de negociação entre as pessoas envolvidas, pois o que se espera obter por meio dela é a condição favorável para que a aula flua da melhor forma possível rumo a uma convivência escolar democrática, pautada na adesão de todos (DAYAN, 2008).

Um ingrediente muito relevante para diminuir a percepção da diferença entre os conceitos é que embora os conceitos indisciplina e violência não sejam sinônimos, a violência pode se desenvolver por meio da conduta indisciplinar (DAYAN, 2008), impondo assim a imprescindibilidade da delimitação de seus significados ante a ocorrência do fato.

\title{
O controle do estado e a promoção da segurança institucional
}

O Estado Democrático de Direito tomou para si a responsabilidade de atender as demandas sociais e, para isso, utiliza a Administração Pública como instrumento, cuja função, conforme descreve Pereira (2007, p.3), é “[...] atuar como eixo transmissor entre Estado e sociedade".

Assim, a Administração Pública, como estrutura do Poder Executivo, volta-se para a coordenação e realização de políticas públicas dirigidas ao interesse comum da 
sociedade (PEREIRA, 2007), que é titular de direitos fundamentais previstos na Constituição Federal (BRASIL, 1988).

Nesse momento, é necessário esclarecer que os direitos fundamentais foram surgindo, e ainda surgem, em diferentes épocas, recebendo a denominação de "gerações" pelo fato de ingressarem na ordem jurídica de acordo com a necessidade que o contexto de diferentes épocas impõe.

De acordo com o tema proposto no presente estudo, conveniente se faz ressaltar os direitos fundamentais compreendidos como de segunda geração, como, por exemplo, o direito à educação, moradia, saúde e ao trabalho, porque esses surgiram em decorrência do impacto dos graves problemas provenientes da industrialização, impondo ao Estado a necessidade de assumir um comportamento ativo frente às demandas sociais.

De acordo com Sarlet (2004), diante da constatação de que a garantia da liberdade e igualdade, direitos fundamentais de primeira geração, não eram suficientes para preservar a classe operária dos males que assolavam a época, as reivindicações apontavam no sentido de que evitar a intervenção do Estado no campo das liberdades individuais não era mais o suficiente para proporcionar o bem estar social. Nesse contexto reivindicou-se o agir do Estado de forma que o pensamento vigente na época era de que "[...] não se cuida mais da liberdade perante o Estado, e sim de liberdade por intermédio do Estado". (SARLET, 2004, p.55).

Assim, além de o Estado, na concepção de Pereira (2007), assumir o papel de interventor das regras que permeiam a economia, também, por imposição de lei, o Estado possui a obrigação de efetivar direitos fundamentais que estão estritamente ligados à vida com dignidade, de forma que:

Desde 1824 até os dias de hoje a Constituição brasileira caracteriza-se por outorgar ao indivíduo direitos e prestações sociais estatais, como assistência social, saúde, educação, trabalho, segurança, etc..., revelando uma transição das liberdades individuais abstratas para as liberdades materiais concretas [...]. (SARLET, 2004, p.55).

Longe dos direitos fundamentais constituírem uma declaração demagoga de atuação estatal, eles impõem uma obrigação de fazer do Estado.

Assim, com o aumento discrepante da criminalidade e da violência, o poder público atentou-se às escolas, mesmo porque os diferentes meios de comunicação, por 
meio da divulgação de notícias impressionantes relacionadas à violência nas escolas tem desafiado o Estado a posicionar-se perante a sociedade (CIESLAK; FERREIRA, 2008).

Nesse sentido, havendo a constatação de um grave comprometimento da educação em decorrência de problemas relacionados à segurança, o Estado busca a resolução dos conflitos, por meio de programas, porém nem sempre com a eficiência que se espera. Assim, Gonçalves e Spósito (apud CIESLAK; FERREIRA, 2008) afirmam que as políticas públicas destinadas à redução da violência nas escolas sempre atuaram de forma insuficiente.

Com o agravamento da situação, que era visivelmente constatada não apenas por meio da mídia, mas também do aumento dos registros de ocorrências realizadas pelas escolas, a polícia passou a intervir de forma mais intensa, sendo que no ano de 2004 a Polícia Militar do Paraná traçou novas estratégias para intervenção no estado, como medida de segurança preventiva e repressiva no espaço escolar (CIESLAK; FERREIRA, 2008).

\section{O programa da patrulha escolar na cidade de Londrina}

A violência e insegurança nas escolas não é um fenômeno exclusivo de países subdesenvolvidos. De acordo com Spósito (1994), aproximadamente 70\% dos colégios americanos revistam seus alunos na entrada e fazem inspeções inesperadas em salas de aula. Em relação à educação na França, Dugléry (apud CIESLAK; FERREIRA, 2008, p.14) expressou sua preocupação com a questão da violência nas escolas e chegou a afirmar que o "[...] fenômeno da violência ao redor das escolas é ainda mal compreendido do ponto de vista da abordagem estatística e deve mobilizar os diferentes atores sociais e singularmente os policiais".

Em decorrência do agravamento da criminalidade e da violência nas escolas, bem como da pressão que a mídia realiza ao salientar a questão, o Poder Público “[...] voltou os olhos para a escola.” (CIESLAK; FERREIRA, 2008, p.21). Assim, quanto à intervenção do Estado nas escolas por meio da polícia, fazem a seguinte afirmação:

É possível estabelecer uma relação inversa entre a violência e a segurança, ou seja, onde está presente uma necessariamente a outra estará ausente. Este é o desafio encontrado pela Polícia Militar no sentido de se fazer presente, real ou potencialmente, em todos os locais de risco de irrupção da violência. Como a ubiquidade é algo impossível de se alcançar, percebe-se que a melhor forma de buscar a 
solução para essa equação é adotar uma estratégia que produza nos destinatários dos serviços policiais a cultura da segurança e da paz (CIESLAK; FERREIRA, 2008, p.19).

No Paraná, a Polícia Militar, junto à Secretaria Estadual de Educação (SEED) fez uma parceria em busca de mecanismos voltados à diminuição dos delitos que ocorrem nas escolas. Assim, foi instituída uma coordenação estadual composta por dois setores:

[...] um de caráter político-institucional ligado à Casa Militar da Governadoria e outro de caráter técnico-operacional, vinculado diretamente ao Estado-Maior da Polícia Militar do Paraná e composto por Oficiais e Praças da PMPR e uma representante da Secretaria de Estado da Educação (SEED). (CIESLAK; FERREIRA, 2008, p.53).

A proposta da Patrulha Escolar, conforme consta no site da SEED, não se restringe ao campo da repressão de práticas criminais que ocorrem no ambiente escolar, mas também no de prevenção. Nesse sentido, Cieslak e Ferreira (2008, p.54) salientam que:

\begin{abstract}
A ênfase da PEC, portanto, está na atuação preventiva com vistas à segurança, procurando antecipar-se aos fatos delituosos em parceria com a comunidade escolar. Essa missão é cumprida precipuamente nas escolas da rede pública estadual, pois nas escolas particulares e municipais o atendimento é feito de forma circunstancial em face de algum problema pontual. A ênfase nas escolas estaduais, decorre da constatação estatística de que a concentração dos problemas de segurança está nesses locais.
\end{abstract}

O PROERD ${ }^{5}$, de acordo com a Diretriz 006/2000 da Polícia Militar, tem por base o projeto DARE ${ }^{6}$, desenvolvido pelo departamento de polícia de Los Angeles (EUA), em que a ação da polícia volta-se para a prevenção contra o uso de drogas, ações de vandalismos, formação de gangues e qualquer forma de violência nas escolas. Esse programa, aplicado pela Patrulha Escolar, enfatiza a prevenção de crimes por meio de palestras interativas com os alunos, prestar assessoria às escolas quanto à segurança (Diretriz PEC).

Assim, segundo consta no site da PEC, em busca do reforço da prática preventiva, a estratégia de sua atuação organiza-se em cinco etapas:

\footnotetext{
${ }^{5}$ Programa Educacional de Resistência às Drogas e à Violência.

${ }^{6}$ Drug Abuse Resistance Education.
} 
A primeira etapa consiste na análise das instalações físicas da escola, como por exemplo, a verificação da iluminação, muros e portões que podem ou não facilitar o acesso de pessoas estranhas à escola (PARANÁ, 2009).

$\mathrm{Na}$ segunda etapa, um diagnóstico da situação da escola é entregue à própria comunidade escolar, para que, se possível, as alterações sejam realizadas como medida de segurança. O objetivo dessa etapa, além de diagnosticar a situação física da escola, é informar a comunidade escolar de sua situação, por meio de:

[...] aplicação de dinâmicas aos pais, professores, funcionários e alunos de cada escola, que ao final indicará o compromisso de cada segmento e determinará o plano de ação e o plano de palestras necessário para a mudança da realidade encontrada ao início dos trabalhos. (PARANÁ, 2009).

Na sequência, é necessário que as providências apontadas na fase diagnóstica sejam tomadas pela comunidade escolar, para dar início ao próximo plano de ação, que consiste na realização de palestras proferidas pela instrutora do PROERD aos alunos da instituição (PARANÁ, 2009).

As onze palestras proferidas aos alunos das escolas Estaduais, de acordo com o plano de aula assinado pelo Major Loemir Mattos de Souza e pela coordenadora estadual operacional da PEC/SEED, não devem exceder o tempo de 15 minutos, devendo ser registradas em ata da escola. Os assuntos abordados pelos instrutores têm como objetivo orientar os alunos sobre cuidados a serem tomados na entrada e saída da escola, a necessidade de evitar brigas, envolvimentos com substâncias ilícitas, como agir com a presença de pessoas estranhas na escola, preservação do patrimônio público, necessidade de respeitar o próximo, orientação quanto ao risco de más influências em rodas de amigos, informar quanto ao risco de aceitar carona de pessoas estranhas, respeito às diferenças econômicas, sociais, físicas de seus colegas (SOUZA; LEMES, 2008).

Na última etapa do programa, elabora-se um “[...] Plano de Segurança por comissão representativa de todos os segmentos da comunidade escolar, descrevendo e registrando todas as providências tomadas para se atingir as melhorias que o foram ao final dos trabalhos”. (PARANÁ, 2009).

$\mathrm{Na}$ cidade de Londrina, há apenas uma instrutora do PROERD, a Cabo Terezinha Santinha Fonseca. De acordo com o Capitão da $4^{\mathrm{a}}$ Companhia do Paraná, situada na cidade de Londrina, as escolas têm solicitado muito esse serviço, porém para 
atender a demanda, seria imprescindível o aumento do número de instrutores. Quanto à questão do número de efetivos, Cieslak e Ferreira (2008, p.63) ponderam que:

Para se conseguir a prevenção ideal é necessário que os destinatários dos serviços sintam-se atendidos plenamente, quer seja real, quer seja potencialmente. Entretanto, o BPEC já se ressente com uma carência recorrente e típica de todas as unidades da Polícia Militar do Paraná: a escassez de recursos humanos.

Em entrevista concedida no dia 19 de agosto de 2009, um sargento da PEC afirmou que a polícia não se importa em fazer mediação entre alunos indisciplinados e professores ou diretores, porém devido ao número reduzido de efetivos frente ao número de escolas que necessitam do atendimento, seria interessante que as escolas pudessem lidar com os assuntos restritos ao campo da indisciplina. Nesse sentido, Cieslak e Ferreira (2008), quanto à postura das escolas diante de situações que residem no âmbito da indisciplina ressaltou que:

[...] muito embora todas essas manifestações afetem o ambiente escolar, nem todas necessitam da intervenção da polícia para a sua resolução. Entretanto, por muito tempo, simples casos de indisciplina, que poderiam ser resolvidos de acordo com o estatuto de cada escola, passaram a ser alvo do acionamento policial para, segundo diretores, professores e funcionários, "dar um susto" nos alunos rebeldes, remetendo à polícia uma função eventualmente educativa, por trás da presença ostensiva, que lhes caberia por obrigação e competência. Esse fenômeno surgiu após o advento do estatuto da criança e do adolescente, e, talvez pelo desconhecimento das regras nele introduzidas - e algum infundado temor -, a escola tenha provocado essa migração. (CIESLAK; FERREIRA, 2008, p.20).

A consideração exposta acima impõe a necessidade de realizar uma verificação acerca da questão sob a percepção dos professores, que será discorrida no tópico subsequente.

\section{O fenômeno da violência e a indisciplina na ótica os professores da rede municipal de ensino da cidade de Londrina/PR}

Tanto a declaração do sargento da patrulha escolar quanto a citação de Cieslak e Ferreira (2008) - enquanto membros pertencentes ao quadro da Polícia Militar-, convergem no sentido de que a dificuldade de lidar com a indisciplina ainda ocorre. 
Com o intuito de verificar essa afirmação nas escolas, foram enviados a trinta professores que atuam na rede municipal e estadual da cidade de Londrina, PR, quatro questões que pretendiam verificar a distinção conceitual quanto ao tema de indisciplina e da violência, bem como para apresentar questões relativas à particular ação da patrulha escolar. No entanto, o universo de questionários reduziu-se a 3 pelo lapso de tempo possível à espera desta coleta para a pesquisa.

Na sequência, evidencia-se o universo do material colhido:

a. Quanto à distinção entre o significado entre violência e indisciplina os professores fizeram as seguintes considerações (grifo nosso):

No meu ver, a violência é o ápice da indisciplina. (Professora 1)

Violência: a pessoa prevalece do uso da força física ou da ação psicológica contra alguém ou contra algo, para atingir determinado fim. Pode ser ato pensado ou não. Indisciplina: a pessoa pratica determinados atos, pensados ou não, em decorrência de costume ou falta de orientação adequada para interagir com outras pessoas ou perante determinada situação. (Professora 2).

Violência é o exercício da força sobre outro. Ela pode ser física, verbal ou comportamental. Geralmente a violência é exercida por alguém que detém o poder num determinado lugar ou hora. Um professor dentro da sala de aula pode ser violento quando menospreza o aluno e/ou o intimida. Quanto à indisciplina é a recusa do cumprimento de regras estabelecidas por um grupo ou por alguém (Professora 3).

\section{b. Quando à constatação de que a patrulha escolar comunitária atende}

chamados relacionados às questões de indisciplina (grifo nosso):

Nos poucos casos que eu precisei, os policiais fizeram o que puderam, mas os alunos não mudaram nada. Na verdade, eles retornaram para a sala de aula contando vantagens, como se tivessem encarado os policiais de homem para homem. Diretora, pedagogas e professores (homens e mulheres) não conseguiam resolver a indisciplina (agressões verbais e físicas entre os colegas de sala; ataques físicos a colegas de idade inferior, de outras turmas; ações de vandalismo nas portas, paredes, carteiras, interruptor elétrico, ventiladores, durante o horário das aulas; recusa em fazer qualquer atividade solicitada pelo professor; conversas em "panelas", no mesmo nível de voz do professor, que tentava dar sua aula; dentre outros pontos) que havia naquela turma em que eu trabalho. Hoje a turma está ótima, porque os "maus elementos" abandonaram os estudos. (Professora 1). 
Sim. Penso que os atos de indisciplina deveriam ser tratados pela Equipe Pedagógica juntamente com os pais. A patrulha deveria ser acionada quando realmente houvesse necessidade. (Professora 2).

Ainda não tive tempo de ver o suficiente para avaliar. O que vi, até agora, é que a patrulha tem sido chamada por questões que poderiam ser administradas pelo professor e/ou escola. Mas o que vi foi muito pouco devido ao tempo de trabalho no Estado. No entanto, desconheço escolas mais periféricas e não fico à vontade de responder com fundamentação. (Professora 3).

c. Quanto ao entendimento de que a violência está presente nas escolas:

Sim, não há dúvidas disso. (Professora 1).

Sim. (Professora 2).

Sim. Aqui, talvez, esteja a confusão dos termos. A indisciplina eleva o nível de stress (?) que gera a violência. A violência está dentro das escolas por uma série de razões. Dentre essas razões a intolerância. (Professora 3).

d. Quanto à colaboração da Patrulha escolar na diminuição da violência nas escolas:

Tive raras experiências com ação da patrulha escolar junto a alunos meus. Então, não tenho muito embasamento para fornecer esta resposta. Nos poucos casos que eu precisei, os policiais fizeram o que puderam, mas os alunos não mudaram nada. $\mathrm{Na}$ verdade, eles retornaram para a sala de aula contando vantagens, como se tivessem encarado os policiais de homem para homem. (Professora 1).

Os patrulheiros são preparados para trabalhar com os adolescentes e controlam bem as ocorrências que envolvem violência no âmbito escolar. Penso que os patrulheiros agem, ao mesmo tempo, como conselheiros, mas sem deixar de intimidar os alunos, e isto acaba controlando e inibindo as ações violentas. (Professora 2).

Acho que sim. (Professora 3).

As respostas acima evidenciadas permitem a realização das seguintes análises: 
1) A clareza quanto à distinção do significado entre violência e indisciplina não foi constatada em todas as respostas. A mesma professora que entende a violência como ápice da indisciplina atribui a uma questão extremamente complexa um conceito muito simplista, no qual a falta de entendimento quanto o assunto ficou mais evidenciada quando a mesma professora realizou suas considerações na questão subsequente relacionada à atuação da patrulha escolar:

Nos poucos casos que eu precisei, os policiais fizeram o que puderam, mas os alunos não mudaram nada. Na verdade, eles retornaram para a sala de aula contando vantagens, como se tivessem encarado os policiais de homem para homem. Diretora, pedagogas e professores (homens e mulheres) não conseguiam resolver a indisciplina (agressões verbais e físicas entre os colegas de sala; ataques físicos a colegas de idade inferior, de outras turmas; ações de vandalismo nas portas, paredes, carteiras, interruptor elétrico, ventiladores, durante o horário das aulas; recusa em fazer qualquer atividade solicitada pelo professor; conversas em "panelas", no mesmo nível de voz do professor, que tentava dar sua aula; dentre outros pontos) que havia naquela turma em que eu trabalho. Hoje a turma está ótima, porque os "maus elementos" abandonaram os estudos (grifo nosso). (Professora 1).

É perceptível, por meio desse depoimento, a confusão dos atos que se misturam na rotina escolar. A desobediência ao comando do docente passa a ser considerada como um ato de violência, misturando-se concomitantemente com os atos realmente constituintes da violência, como por exemplo, dano ao patrimônio, agressões de ordem física e verbal.

2) A confirmação de que a Patrulha Escolar Comunitária tem sido chamada, também, para atender situações resultantes de atos de indisciplina foi unânime. A professora 1, apesar de não ter respondido diretamente a questão, em seu depoimento, ao criticar os resultados da ação dos policiais, deixou subentendido que a polícia é chamada para intervir em assuntos não pertinentes à esfera da indisciplina ao fazer a seguinte afirmação:

[...] recusa em fazer qualquer atividade solicitada pelo professor; conversas em "panelas", no mesmo nível de voz do professor, que tentava dar sua aula; dentre outros pontos) que havia naquela turma em que eu trabalho. Hoje a turma está ótima, porque os "maus elementos" abandonaram os estudos (grifo nosso). (Professora 1). 
As demais professoras compreendem que o assunto relacionado à esfera da indisciplina deve ser tratado pela escola, embora presenciem a solicitação desnecessária da polícia.

3) Houve confirmação de que a violência tem sido fato presente nas escolas, sendo que a maioria confirma a importância da Patrulha Escolar para a sua redução. Porém, a professora número 1 assinalou que ainda que contassem com a presença dos policiais na instituição de ensino, os alunos não alteraram o comportamento, apesar de todo o cuidado que os policiais tiveram para procurar resolver o caso. As demais professoras questionadas apenas tecem observações quanto à importante atuação dos policiais nos conflitos instalados na rotina escolar.

Constata-se que as demais professoras que tinham uma percepção um pouco mais apurada sobre a diferença entre violência e indisciplina, compreenderam que a polícia contribui para a diminuição da violência.

Apesar de essa constatação ter sido realizada, é importante ressaltar que a sua causa pode ser decorrente de vários fatores que dependem da análise de fatores que permeiam o contexto do ambiente de trabalho em que cada uma dessas professoras atuam.

Devido à delimitação do objeto do estudo proposto, a ausência desses elementos não permitiria afirmar ao certo os fatores geradores desse fato, porém, uma das possibilidades seria a questão explorada na página 29 deste trabalho, em que Dayan (2008) pondera que um dos fatores que contribuem para a confusão entre o significado de indisciplina e violência reside no fato de a violência desenvolver-se por meio da conduta indisciplinar.

\section{Considerações finais}

O confronto entre a literatura apresentada com a análise dos depoimentos dos policiais e dos professores revela de forma esclarecedora alguns dados muito relevantes que serão pontuadas na sequência.

A violência nas escolas é fato afirmado tanto pelo levantamento teórico quanto pelos dados de realidade. Além dos depoimentos dos policiais da patrulha escolar, as três professoras afirmaram unanimemente que a violência está presente nas escolas, sendo que duas delas afirmam que a atuação da patrulha escolar contribui para a redução da violência. 
Em meio às tensões provenientes do mal estar da violência nas escolas ou até mesmo de sua eminência, é necessário que os profissionais que atuam nas escolas, apesar de todas as dificuldades do próprio ambiente, muitas vezes tenso, tenham a percepção clara da linha limítrofe existente entre a violência e a indisciplina.

As constatações aqui realizadas, não apenas pela literatura, mas também por meio das questões destinadas aos professores quanto à diferença entre indisciplina e violência e quanto à verificação de que a patrulha escolar atende chamados relacionados à indisciplina nas escolas, constituem um dado no mínimo preocupante, pois o relato dos policiais de que a solicitação da polícia para mediar assuntos pertinentes ao campo da indisciplina é comum foi confirmado por todas as professoras nas entrevistas realizadas nesse trabalho, o que demonstra que os profissionais que atuam nas escolas apresentam dificuldades em lidar com a indisciplina.

Frente às relações conturbadas no ambiente escolar, discernir o significado de indisciplina e violência é extremamente importante para delinear os atores mais adequados à demanda da situação: o professor ou a polícia, pois a indisciplina não é caso de polícia, mas sim de didática.

\section{VIOLENCE AND INDISCIPLINE IN THE SCHOOL: A NECESSARY COMPARISON}

ABSTRACT: This study has the intention to make a comparison between the main aspects of the phenomenon of violence and indiscipline in school. We understand the relevance of the subject considering the aspects transcend issues faced before as indiscipline to nowadays being portrayed as acts of extreme violence. To describe those phenomenon's we will perform a literature search, a document search and a survey with the actors directly involved, assistance based on the technical instruments of interviews and questionnaires. Then, we do doctrinal research on the Government speech about the planning to stop the violence. In the last chapter we will emphasize one of the actions proposed in the units of education, highlighting the "Community" school program" in Paraná, especially in the city of Londrina.

KEYWORDS: Violence. Indiscipline. School.

\section{REFERÊNCIAS}

ABRAMOVAY, M. et al. Cotidiano das escolas: entre violências. Brasília: UNESCO, Observatório de Violência, Ministério da Educação, 2005.

ABRAMOVA, M.; RUA, M. G. Violências nas escolas: versão resumida. Brasília: UNESCO, 2003. 
ANTUNES, D. C.; ZUIN, A. A. S. Do bullyng ao preconceito: os desafios da barbárie à educação. Psicologia \& Sociedade, Porto Alegre, v.20, n.1, p.33-42, 2008.

AQUINO, J. G. A violência escola a crise da autoridade docente. Caderno Cedes, Campinas, v.19 n.47, dez. 1998. Disponível em:

<http://www.scielo.br/scielo.php?script=sci_arttext\&pid=S0101-32621998000400002>. Acesso em: 02 set. 2009.

BAUMAN, Z. Modernidade líquida. Tradução de Plínio Dentzen. Rio de Janeiro: Jorge Zahar, 2001.

BRASIL. Constituição (1988). Constituição da República Federativa do Brasil. Brasília, DF: Senado Federal, 1988.

BUENO, F. Minidicionário da língua portuguesa. 2.ed. São Paulo: FTD, 2007.

CANDAU, V. M. (Org). Reinventar a escola. Petrópolis: Vozes, 2000.

CHRISPINO, A.; DUSI, M. L. H. M. Uma proposta de modelagem de política pública para a redução da violência escolar e promoção da cultura da paz. Ensaio: Avaliação e Políticas Públicas em Educação, Rio de Janeiro, v.16, n.61, out./dez. 2008. Disponível em: <http://www.scielo.br/scielo.php?pid=S0104-

$40362008000400007 \&$ script=sci_arttext $>$. Acesso em: 12 jul. 2009.

CIESLAK, A.; FERREIRA, E. C. P. Atuação da patrulha escolar comunitária e segurança nas escolas do estado do Paraná. 2008. Monografia (Especialização em Gestão Estratégica em Segurança Pública) - Universidade Estadual da Bahia/ Polícia Militar da Bahia, Bahia, 2008.

CORTELLA, M. S.; LA TAILLE, Y. Nos labirintos da moral. 5.ed. São Paulo: Papirus, 2009.

DAYAN, S. P. Como enfrentar a indisciplina na escola. São Paulo: Contexto, 2008. Disponível em: <http://www.iea.usp.br/iea/artigos/>. Acesso em: 15 jul. 2009.

DEBARBIEUX, E. et al. Desafios e alternativas: violências nas escolas. Brasília: UNESCO, 2003.

GOMES, V. L. O.; FONSECA, A. D. Dimensões da violência contra crianças e adolescentes apreendidas no discurso de professoras e cuidadoras. Texto \& Contexto Enfermagem, Florianópolis, v.14, 2005. Disponível em: <http://www.scielo.br/scielo.php?pid=S0104-07072005000500004\&script=sci_arttext>. Acesso em: 20 ago. 2009.

LIBÂNEO, J. C. Didática. São Paulo: Cortez. 1994.

LUCKESI, C. C. Avaliação da aprendizagem escolar. São Paulo: Cortez: 1994. 
MEMÓRIA E MOVIMENTOS SOCIAIS. Banco de imagens memórias e movimentos sociais [online]. Disponível em:

<http://www.memoriaemovimentossociais.com.br/bancodeimagens/displayimage.php?a lbum $=1 \&$ pos=174> . Acessado em: 15 set. 2009.

MOORE JR, B. Injustiça: as bases sociais da obediência e da revolta. Tradução de João Roberto Martins Filho. São Paulo: Brasiliense, 1987.

PEREIRA, J. M. Manual de gestão pública contemporânea. São Paulo: Atlas, 2007.

PARANÁ. Portal Educacional do Estado do Paraná. Patrulha escolar comunitária. Curitiba: Polícia Militar do Paraná, 2009. Disponível em:

<www8.pr.gov.br/portals/.../patrulhaescolar/index.php>. Acesso em: 12 ago. 2009

RIOS, T. A. A dimensão ética da aula ou o que nós fazemos com eles. In: VEIGA, I. P. A. (Org). Aula: gênese, dimensões, princípios e práticas. Campinas: Papirus, 2008. p.73-93.

RUOTTI, C.; ALVES, R.; CUBAS, V. O. Violência na escola: um guia para pais e professores. São Paulo: Andhep, Imprensa Oficial do Estado de São Paulo, 2006.

SARLET, I. W. A eficácia dos direitos fundamentais. Porto Alegre: Livraria dos advogados, 2004.

SOUZA, L. M.; LEMES, M. M. Plano de aula patrulha escola comunitária. [S.l.]: [S.d], 2008.

SPÓSITO, M. P. A instituição escolar e a violência. Cadernos de Pesquisa, São Paulo: Fundação Carlos Chagas, n.104, p.58-75, 1998. Disponível em:

<http://www.iea.usp.br/iea/artigos/>. Acesso em: 30 ago. 2009.

THOMPSON, E. P. A formação da classe operária inglesa. Tradução de Denise Boethmann. Rio de Janeiro: Paz e Terra, 2002. 